Syntax Literate: Jurnal Ilmiah Indonesia p-ISSN: 2541-0849

e-ISSN: 2548-1398

Vol. 6, No. 7, Juli 2021

\title{
ANALISIS PENURUNAN TANAH DENGAN PLAXIS 2D DAN 3D PADA PROYEK REKLAMASI BELAWAN
}

\section{Rudianto Surbakti}

Universitas Medan Area (UMA) Medan Sumatera Utara, Indonesia

Email: rudianto@staff.uma.ac.id

\begin{abstract}
Abstrak
Penurunan tanah adalah masalah yang sering ditemukan pada konstruksi diatas tanah lunak selain pergerakan tanah dan pergeseran tanah. Tanah dengan konsistensi lunak dan memiliki permeabilitas rendah akan lambat mengalirkan air pori dalam tanah sehingga diperlukan penanganan khusus untuk mempercepat prosesnya. Salah satu metode untuk mempercepat proses pengaliran air pori pada tanah dasar yaitu dengan memberikan beban Preloading dan pemancang PVD (Prefabricated Vertical Drain). PVD mampu mempercepat keluarnya air pori tanah sehingga proses konsolidasi bisa berlangsung lebih cepat. Data harian penurunan tanah yang terjadi di lapangan dicatat dari settlement plate yang dipasang di lapangan. Analisis ini bertujuan untuk mengetahui perbandingan antara penurunan tanah yang dihitung menggunakan program Plaxis 2D dan 3D dibandingkan dengan penurunan yang tercatat pada settlement plate. Analisis menunjukkan bahwa besar penurunan yang terjadi pada Plaxis 2D adalah 6,47 meter dan dari analisis Plaxis $3 \mathrm{D}$ adalah 6,356 meter. Penurunan yang terjadi menurut pengamatan settlement plate di lapangan adalah 6,32 meter. Dapat disimpulkan bahwa analisis dengan menggunakan Plaxis 3D lebih mendekati penurunan hasil observasi dibandingkan dengan menggunakan Plaxis 2D.
\end{abstract}

Kata Kunci: preloading, PVD (Pre-fabricated Vertical Drain), Plaxis, penurunan tanah.

\section{Abstract}

Land subsidence is a problem that is often found in construction on soft soil other than displacement and disposition of soil. Soil with a soft consistency and low permeability will slowly drain the pore water in the soil so special handling is needed to speed up the process. One of the methods to speed up the process of pore water drainage in the subgrade is by applying the preloading load and staking the PVD (Pre-fabricated Vertical Drain). PVD is able to accelerate the discharge of soil pore water so that the consolidation process can take place faster. Daily data of land subsidence that occurs in the field are recorded from the settlement plates installed in the field. This analysis aims to determine the comparison between settlement of soil which calculated using the Plaxis $2 D$ and $3 D$ program compared to the settlement recorded on the settlement plate. The analysis shows that large of settlement that occurred in Plaxis 2D was 6.47 meters and from Plaxis $3 D$ analysis was 6.356 meters. While the settlement that occurred according to observations of

$\begin{array}{ll}\text { How to cite: } & \text { Surbakti, Rudianto (2021) Analisis Penurunan Tanah dengan Plaxis 2D dan 3D pada Proyek } \\ & \text { Reklamasi Belawan. Syntax Literate: Jurnal Ilmiah Indonesia. 6(7). http://dx.doi.org/10.36418/ } \\ & \text { syntax-literate.v6i7.1532 } \\ & \text { 2548-1398 } \\ \text { E-ISSN: } & \text { Ridwan Institute }\end{array}$


settlement plates in the field was 6,32 meters. It can be concluded that the analysis using Plaxis $3 D$ is closer to the observation settlement compared to using Plaxis $2 D$.

Keyword: preloading, PVD (Pre-fabricated Vertical Drain), Plaxis, settlement of soil.

\section{Pendahuluan}

Sifat tanah lunak yang buruk menyebabkan diperlukannya penelitian mendalam mengenai potensi penurunan tanah yang terjadi. Faktor-faktor yang menyebabkan tanah lunak memiliki karakteristik buruk adalah karena tanah ini memiliki kadar air yang tinggi, ukuran butiran yang kecil serta gradasi butiran yang buruk (Andriani, Yuliet, \& Fernandez, 2012). Kadar air tanah dapat dikurangi maka daya dukung dan sudut gesernya dapat ditingkatkan, namun proses menurunkan kadar air ini menjadi sulit dikarenakan permeabilitas tanah yang sangat rendah. Dikarenakan tanah lunak memiliki kuat geser rendah dan kompresibilitas tinggi, jika tidak diselidiki dengan seksama akan menyebabkan ketidakstabilan dan penurunan tanah yang berbahaya bagi konstruksi (Permukiman \& Wilayah, 2002).

Mengatasi hal ini maka perlu dilakukan penanganan tanah agar air tanah dapat keluar dan tanah dapat terkompresi sehingga dapat meningkatkan daya dukungnya. Penambahan PVD untuk menaikkan permeabilitas tanah dan penambahan beban preloading merupakan salah satu metode yang umum digunakan untuk menangani tanah-tanah lunak. Metode pembebanan awal (preloading) dan drainase vertikal mampu untuk meningkatkan kekuatan geser tanah lunak dan mengeluarkan air pori dalam tanah (Xu, 2017).

Metode element hingga menggunkan Plaxis sangat umum digunakan untuk menganalisa masalah-masalah geoteknik. Dimana progam ini mampu menghitung dan menganalisa berbagai masalah geoteknik seperti penurunan, pergerakan dan tegangantegangan yang beerja (Pertiwi, 2014). Program ini dirancang untuk dapat melakukan pembuatan geometri yang akan dianalisa. Berdasarkan data tanah hasil penyelidikan geoteknik dan laboratorium yang diperoleh dari lapangan dapat dihasilkan potensi besar penurunn yang akan terjadi (Rujikiatkamjorn, Indraratna, \& Chu, 2008).

Berapa besar penurunan tanah yang terjadi dapat dihitung dan dianalisa dengan finite element method yaitu dengan menggunakan software Plaxis 2D dan 3D. Penurunan sebenarnya yang terjadi di lapangan dicatat melalui penurunan settlement plate yang dipasang (Hird, Pyrah, Russell, \& Cinicioglu, 1995). Hasil perhitungan penurunan tanah dari pemodelan 2D dan 3D dapat dibandingkan sehingga diperoleh metode mana yang paling mendekati penurunan yang sebenarnya di lapangan. Masih menjadi perdebatan manakah yang lebih efisien dalam menggunakan Plaxis 3D atau 2D sebagai penentu besar penurunan yang akan terjadi di lapangan. Penelitian ini bertujuan untuk mengtahui manakah software yang paling efektif digunakan dalam perencanaan konstruksi diatas tanah lunak. Manfaat dari penelitian ini adalah untuk memudahkan para perencana konstruksi untuk menentukan manakah antara Plaxis 2D dan 3D yang paling efisien digunakan dalam perencanaan proyek. Analisis ini bertujuan untuk 
mengetahui perbandingan antara penurunan tanah yang dihitung menggunakan program Plaxis 2D dan 3D dibandingkan dengan penurunan yang tercatat pada settlement plate.

\section{Metode Penelitian}

Metode yang digunakan dalam penelitian ini adalah memodelkan dimensi pekerjaan reklamasi serta tahapan-tahapan penimbunannya dengan menggunakan software Plaxis 2D dan 3D. Dimana data-data yang diperlukan untuk proses analisis data diperoleh dari hasil laboratorium dan pengujian lapangan yang dilakukan pada proyek tersebut.

Penelitian ini, yang fokus menjadi tinjauan penelitian adalah lokasi reklamasi yang menggunakan metode pra-pembebanan yang digbungkan dengan pemasangan prefabricated vertical drain. Pekerjaan reklamasi ini akan berdampingan langsung dengan lokasi pengerukan alur nelayan, sehingga pada perhitungan nantinya harus memperhitungkan kedalaman pengerukan yang telah dikerjakan, hal ini dimaksudkan agar hasil perhitungan yang dilakukan dapat diperoleh dengan hasil seakurat mungkin (Sengul, Edil, \& Ozaydin, 2017).

Ada beberapa tahapan dalam proses analisis data yang dilakukan pada penelitian ini, mulai dari analisa hasil pengujian laboratorium sampel tanah sampai proses perhitungan dengan menggunakan Plaxis 2D dan 3D. Sebagai pembanding antara perhitungan Plaxis 2D dan 3D dengan penurunan sebenarnya di lapangan digunakan data settlement plate S-13, yang mana lokasinya paling dekat dengan lokasi pengujian tanah di lapangan (Tjie-Liong, 2014).

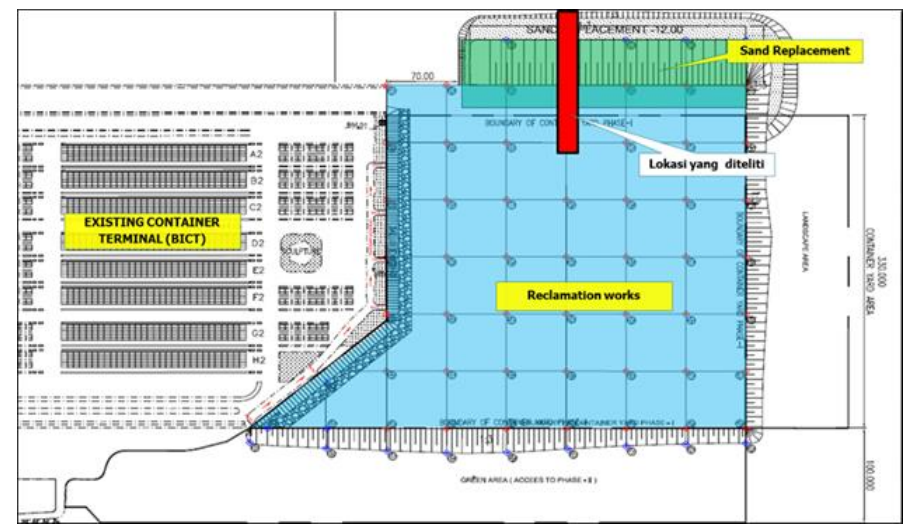

Gambar 1

Lokasi yang Dimodelkan dalam Penelitian

Sumber: Penulis 


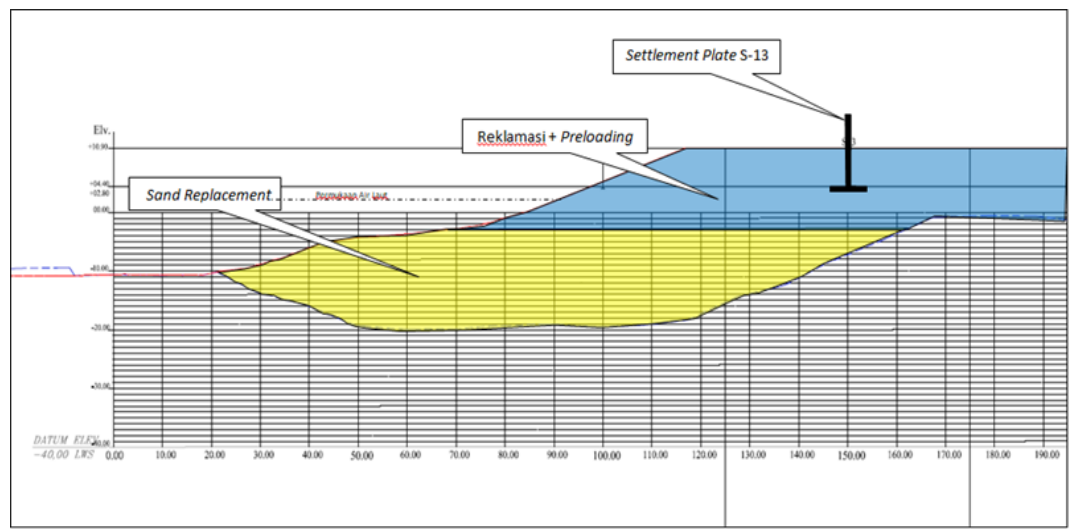

Gambar 2

Potongan Melintang Lokasi yang Dianalisis setelah Selesai Pekerjaan Preloading Sumber: Penulis

Tahapan-tahapan yang dilakukan pada proses penelitian adalah sebagai berikut: Tahap pertama, pengumpulan data properties tanah dari hasil laboratorium, data settlement plate S-13, data properties tanah timbun yang digunakan, dan stratifikasi tanah yang diperoleh dari hasil boring BH-02. Tahap kedua: perhitungan waktu dan tahapan proses penimbunan yang diambil dari data settlement plate S-13, mulai dari galian sand replacement sampai dengan elevasi puncak penimbunan. Tahap ketiga: perhitungan efek smear zone yang diakibatkan oleh pemancangan pre-fabricated vertical drain dengan menggunakan Mandrel. Tahap keempat: perhitungan waktu dan kedalaman penurunan (konsolidasi) tanah dengan kombinasi pra-pembebanan dan PVD menggunakan Plaxis 2D dan 3D. Tahap kelima: membandingkan dan menganalisa hasil perhitungan dengan realisasi penurunan yang terjadi di lapangan (Iskandar \& Silalahi, 2018).

\section{Hasil dan Pembahasan}

Waktu pelaksanaan yang dubutuhkan untuk setiap tahapan pekerjaan lapangan dapat diperoleh dari data pengukuran harian yang terdapat pada settlement plate S-13. Dimana pada data settlement plate selain tercatat penurunan instrument juga tercatat penambahan elevasi tanah timbunan setiap harinya. Dari data ini diketahui berapa lama waktu yang dibutuhkan untuk menaikkan elevasi timbunan pada setiap tahapan pekerjaannya. Dimana tahapan-tahapan pelaksanaan pekerjaannya adalah sebagai berikut:

1. Tahap 1 : Pekerjaan galian tanah untuk penimbunan sand replacement selama 30 hari

2. Tahap 2 : Pekerjaan timbunan sand replacement selama 10 hari

3. Tahap 3: Pekerjaan timbunan underwater selama 3 hari

4. Tahap 4: pekerjaan timbunan above water selama 3 hari

5. Tahap 5: konsolidasi timbunan selama 6 hari

6. Tahap 6: pemasangan PVD dan settlement plate selama 10 hari.

7. Tahap 7: penimbunan preloading tahap 1 setinggi 1,5 meter selama 43 hari.

8. Tahap 8: penimbunan preloading tahap 2 setinggi 0,7 meter selama 1 hari. 
9. Tahap 9: penimbunan preloading tahap 3 setinggi 2,6 meter selama 1 hari.

10. Tahap 10: penimbunan preloading tahap 4 setinggi 0,8 meter selama 1 hari.

11. Tahap 11: penimbunan preloading tahap 5 setinggi $1,1 \mathrm{~m}$ selama 7 hari.

12. Tahap 12: konsolidasi akhir timbunan selama 89 hari.

Memodelkan pekerjaan galian dan timbunan agar sesuai dengan kondisi sebenarnya di lapangan, ada beberapa kondisi yang harus diperhatikan yaitu: pertama, initial condition dimana kondisi penampang belum dilakukan galian untuk sand replacement. Kedua, kondisi setelah dilakukan galian sand replacement sebelum dilakukan penimbunan, pada kondisi ini galian terbuka akan menyebabkan pergerakan tanah menuju galian tersebut. Ketiga, kondisi setelah dilakukan penimbunan sand replacement, reklamasi dibawah elevasi air laut dan reklamasi diatas elevasi air laut. Keempat, kondisi setelah dipasangkan Pre-fabricated Vertical Drain (PVD) dimana pada kondisi ini PVD yang sudah dimodelkan diaktifkan dan tanah akan mengalami percepatan penurunan konsolidas dan kelima kondisi pada saat dilakukan preloading dimana tahapan penimbunannya harus sesuai dengan kondisi sebenarnya di lapangan (Indraratna, Bamunawita, Redana, \& McIntosh, 2003).

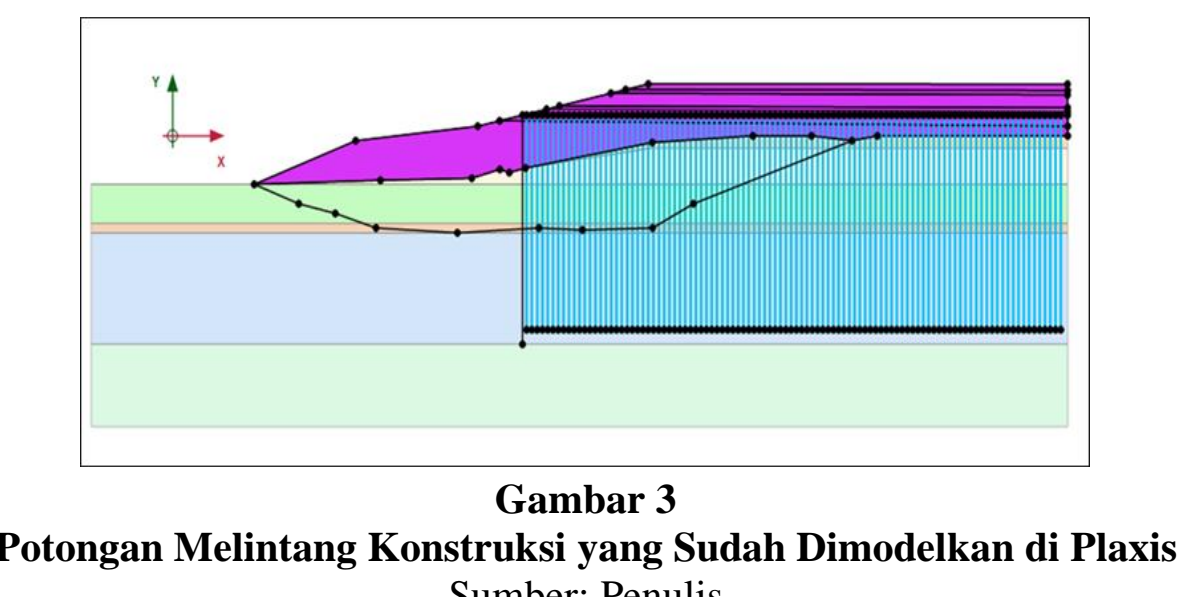

Sumber: Penulis

Seluruh tahapan perhitungan dimasukkan ke dalam program Plaxis 2D dengan benar, maka program dapat melakukan perhitungan. Hasil output perhitungannya menunjukkan bahwa penurunan vertikal yang terjadi berada dibawah timbunan preloading adalah 6,615 meter, sedangkan pada titik tinjauan yaitu lokasi pemasangan settlement plate terjadi penurunan sebesar -6.470 meter (Setyanto, Zakaria, \& Giwa, 2016). 


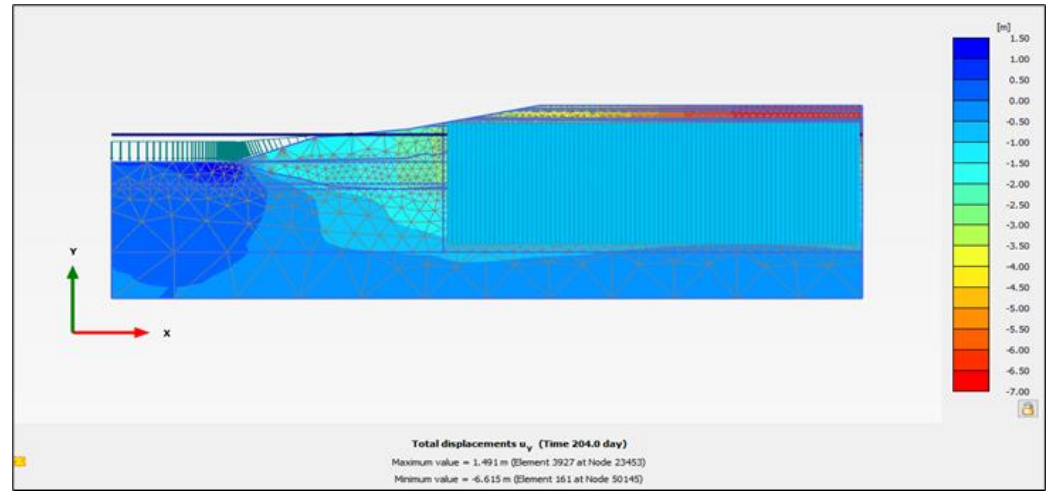

Gambar 4

Penyebaran Penurunan pada Model Plaxis 2D

Sumber: Penulis

Hubungan antara waktu pelaksanaan pekerjaan dengan penurunan yang terjadi pada titik tinjauan settlement plate S-13 dapat dilihat pada grafik berikut ini:

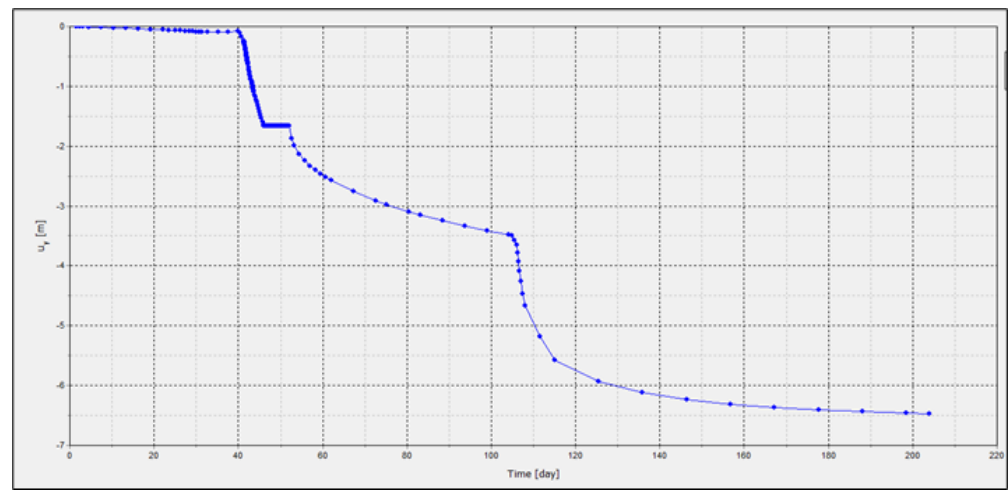

\section{Gambar 5}

Grafik Hubungan Antara Vertical Displacement dengan Waktu di Titik Settlement Plate S-13

Sumber: Penulis

Sama halnya dengan permodelan dengan Plaxis 2D, pada Plaxis 3D langkah awal yang harus dilakukan adalah memodelkan geometri tanah yang akan dianalisis. Model penampang lapisan tanah pada Plaxis 3D digambarkan 1 baris PVD dimana lebar model adalah 1,5 meter. Sedangkan panjang permodelan adalah 200 meter untuk mengakomodir keseluruhan struktur yang ada dilapangan yaitu sand replacement dan preloading (Li, Vaudel, Zhang, Ren, \& Wen, 2019). Tahapan-tahapan perhitungan yang sama dengan model di Plaxis 2D, diperoleh hasil perhitungan penurunan di Plaxis 3D adalah 6,356 meter dengan penyebaran penurunan tanah dasar seperti gambar berikut: 


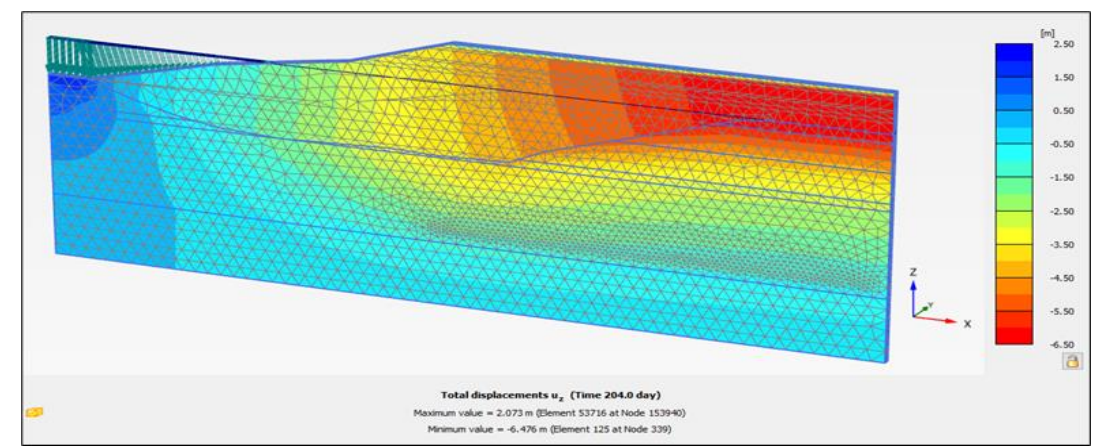

Gambar 6

Penyebaran Penurunan Tanah pada Model Plaxis 3D

Sumber: Penulis

Grafik penurunan tanah terhadap waktu pelaksanaan pekerjaan menunjukkan bagaimana pola penurunan tanah yang terjadi. Dari grafik terlihat bahwa ketika pekerjaan galian sand key, lapisan tanah di lokasi tinjauan mengalami penurunan akibat lateral displacement. Kemudian lapisan tanah mengalami vertical displacement pada saat sand replacement ditimbun pasir. Vertical Displacement yang terjadi disebabkan oleh adanya tegangan yang diberikan oleh pasir timbun yang menyebabkan terangkatnya lapisan-lapisan dengan tegangan yang lebih rendah (Ueng, 2012).

Penurunan terjadi dengan lambat ketika PVD belum dipasang dan semakin cepat setelah PVD dipasang menembus lapisan tanah lunak. PVD mampu menaikkan permeabilitas tanah sehingga desipasi air posi semakin cepat. Masa tunggu preloading selama 89 hari, grafik penurunan tanah mulai melambat sampai akhirnya tidak terjadi penurunan tanah lagi (Nguyen, Yun, \& Kim, 2018).

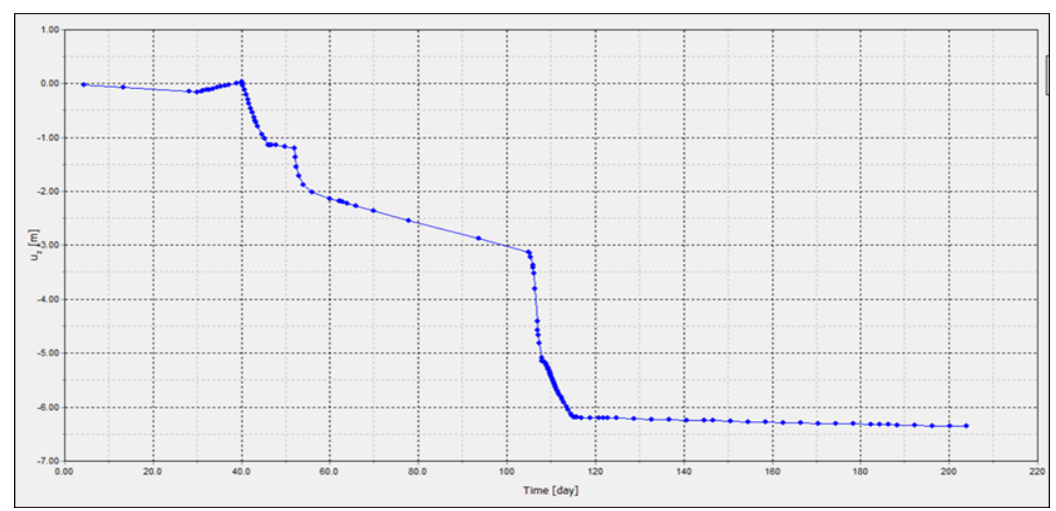

\section{Gambar 6}

Grafik Hubungan Antara Vertical Displacement dengan Waktu Di Titik Settlement Plate S-13

Sumber: Penulis

Kedua permodelan yang menggunakan data-data dan karakteristik tanah yang sama, namun permodelan pertama menggunakan program Plaxis 2D dan permodelan kedua Plaxis 3D, diketahui bahwa penurunan tanah yang terjadi dari permodelan Plaxis 
3D lebih dekat dengan penurunan observasi lapangan. Hasilnya seperti tertera pada tabel berikut:

\section{Tabel 1}

Rekapitulasi Hasil Perhitungan Penurunan Tanah

\begin{tabular}{|c|c|c|c|c|}
\hline Permodelan & $\begin{array}{c}\text { Berdasarkan } \\
\text { Settlement Plate } \\
(\mathrm{m})\end{array}$ & $\begin{array}{l}\text { Prediksi } \\
\text { Penurunan }\end{array}$ & $\begin{array}{c}\text { Perbedaan } \\
\text { Penurunan Prediksi } \\
\text { dengan Lapangan } \\
(\mathrm{cm})\end{array}$ & $\begin{array}{c}\text { Persentasi } \\
\text { Perbedaan } \\
\text { Penurunan } \\
\quad(\%)\end{array}$ \\
\hline PLAX & \multirow{2}{*}{-6.320} & -6.470 & $-15,036$ & 2,379 \\
\hline PLAXIS 3D & & -6.356 & -3.58 & 0.566 \\
\hline
\end{tabular}

Sumbar: Penulis

Hasil penelitian sebelumnya yang dilakukan (Hayati, 2019) menyimpulkan bahwa penurunan hasil pemodelan Plaxis 3D lebih mendekati aktual lapangan. Hasil tersebut senada dengan hasil dari penelitian ini. Plaxis 3D juga menunjukkan pada saat konsolidasi akhir selama 89 hari, penurunan tanah tidak terlalu signifikan dan stabil. Plaxis 2D menunjukkan bahwa penurunan masih relatif besar di awal-awal waktu konsolidasi akhir (Napitupulu, Roesyanto, \& Iskandar, 2021). Perbandingannya pola penurunan tanah hasil analisis Plaxis 2D dan 3D dapat dilihat pada gambar berikut ini:

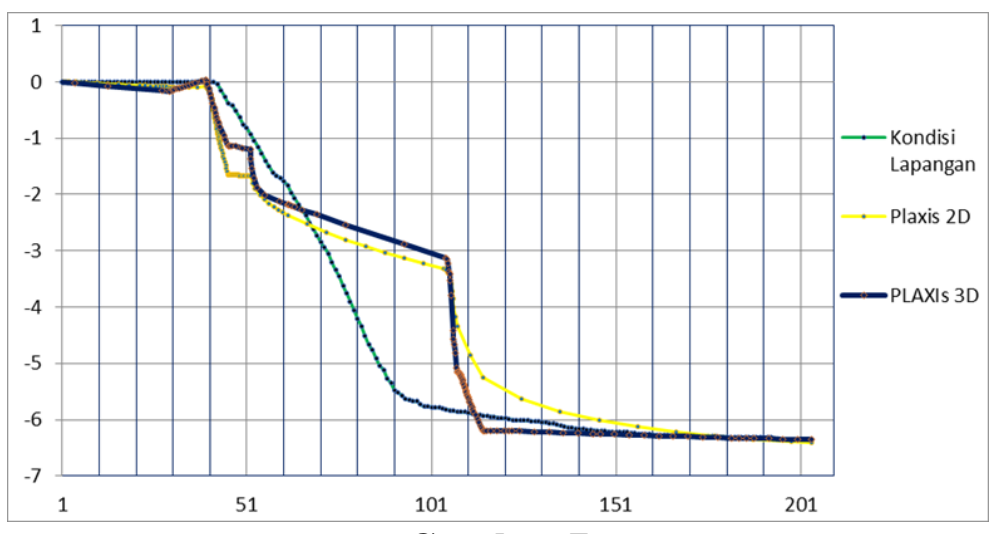

Gambar 7

Perbandingan Pola Penurunan Model Plaxis 2D, Plaxis 3D dan Aktual Lapangan Sumber: Penulis

\section{Kesimpulan}

Penurunan konsolidasi menggunakan pemodelan Plaxis 3D memberikan hasil yang lebih mendekati keadaan sebenarnya di lapangan dibandingkan dengan pemodelan Plaxis 2D. Hasil perhitungan dan pola penurunan tanah dengan Plaxis 3D lebih akurat dibandingkan dengan hasil perhitungan Plaxis 2D. Plaxis 3D lebih mendekati kondisi sebenarnya dilapangan dikarenakan pergerakan tanah dianalisis ke sumbu $\mathrm{x}, \mathrm{y}$ dan $\mathrm{z}$ yang merupakan gambaran sebenarnya lapangan. Penelitian berikutnya dapat diteliti efek penggunaan alat pancang PVD (smear zone) terhadap permeabilitas tanah dasar terhadap besar penurunan tanah yang terjadi. 


\section{BIBLIOGRAFI}

Andriani, Andriani, Yuliet, Rina, \& Fernandez, Franky Leo. (2012). Pengaruh Penggunaan Semen sebagai Bahan Stabilisasi pada Tanah Lempung Daerah Lambung Bukit terhadap Nilai CBR Tanah. Jurnal Rekayasa Sipil (JRS-Unand), 8(1), 29-44. Google Scholar

Hayati, Titi. (2019). Analisis Pengaruh Smear Zone pada Penurunan dan Waktu Konsolidasi Proyek Reklamasi Belawan Fase II dengan Plaxis 2D dan 3D. Medan: Universitas Sumatera Utara. Google Scholar

Hird, C. C., Pyrah, I. C., Russell, D., \& Cinicioglu, F. (1995). Modelling the effect of vertical drains in two-dimensional finite element analyses of embankments on soft ground. Canadian Geotechnical Journal, 32(5), 795-807. Google Scholar

Indraratna, Buddhima, Bamunawita, C., Redana, I. W., \& McIntosh, G. (2003). Modelling of prefabricated vertical drains in soft clay and evaluation of their effectiveness in practice. Proceedings of the Institution of Civil Engineers-Ground Improvement, 7(3), 127-137. Google Scholar

Iskandar, R., \& Silalahi, S. A. (2018). Soil settlement analysis in soft soil by using preloading system and prefabricated vertical draining runway of Kualanamu Airport. IOP Conference Series: Materials Science and Engineering, 309(1), 1-8. 12024. IOP Publishing. Google Scholar

Li, Kai, Vaudel, Marc, Zhang, Bing, Ren, Yan, \& Wen, Bo. (2019). PDV: an integrative proteomics data viewer. Bioinformatics, 35(7), 1249-1251. Google Scholar

Napitupulu, Melvi Maulita, Roesyanto, Roesyanto, \& Iskandar, Rudi. (2021). Analisa Konsolidasi Di Area Non Sand-Key pada Areal Reklamasi Proyek Pengembangan Pelabuhan Belawan-Phase I Menggunakan Plaxis 2D dan 3D. Syntax Literate; Jurnal Ilmiah Indonesia, 6(1), 311-320. Google Scholar

Nguyen, Ba Phu, Yun, Dae Ho, \& Kim, Yun Tae. (2018). An equivalent plane strain model of PVD-improved soft deposit. Computers and Geotechnics, 103, 32-42. Google Scholar

Permukiman, Departemen, \& Wilayah, Prasarana. (2002). Panduan Geoteknik 4. Edisi Pertama, Jakarta: Departemen Permukiman dan Prasarana Wilayah. Google Scholar

Pertiwi, Dea. (2014). Persyaratan Perencanaan Geoteknik dan keGemPaan. Bandung: Kementerian Pekerjaan Umum Badan Penelitian dan Pengembangan Pusat. Google Scholar

Rujikiatkamjorn, Cholachat, Indraratna, Buddhima, \& Chu, Jian. (2008). 2D and 3D numerical modeling of combined surcharge and vacuum preloading with vertical drains. International Journal of Geomechanics, 8(2), 144-156. Google Scholar 
Sengul, Tayfun, Edil, Tuncer, \& Ozaydin, Kutay. (2017). Laboratory determination of smear and transition zones due to prefabricated vertical drain installation. Marine Georesources \& Geotechnology, 35(7), 895-904. Google Scholar

Setyanto, Setyanto, Zakaria, Ahmad, \& Giwa, Permana. (2016). Analisis Stabilitas Lereng dan Penanganan Longsoran Menggunakan Metode Elemen Hingga Plaxis V. 8.2 (Studi Kasus: Ruas Jalan Liwa-Simpang Gunung Kemala STA. 263+ 650). Journal Rekayasa, 20(2), 119-138. Google Scholar

Tjie-Liong, Gouw. (2014). Common mistakes on the application of Plaxis 2D in analyzing excavation problems. International Journal of Applied Engineering Research, 9(21), 8291-8311. Google Scholar

Ueng, T. S. (2010). Shaking table tests for studies of soil liquefaction and soil-pile interaction. Geotechnical Engineering, 41(1), 77-104. Google Scholar

Xu, Binbin. (2017). Influence of Surcharge Preloading Improvement on Surrounding Environment Based on Plaxis 3D. IOP Conference Series: Earth and Environmental Science, 100(1), 1-6. 12108. IOP Publishing. Google Scholar

\section{Copyright holder:}

Rudianto Surbakti (2021)

First publication right:

Syntax Literate: Jurnal Ilmiah Indonesia

This article is licensed under:

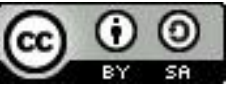

